\title{
Deposit Collecting: Unbundling the Role of Frequency, Salience, and Habit Formation in Generating Savings
}

\author{
By Suresh de Mel, Craig McIntosh, and Christopher Woodruff**
}

\begin{abstract}
Deposit collectors are common in many countries (Ashraf, Karlan, and Yin 2006). Poor households prove willing to pay for services such as Chit collectors in India or Susu collectors in Western Africa, indicating the value of illiquid savings to those whose financial lives are transacted largely in cash (Rutherford 2000). While small-scale deposit collection can provide a valuable service to households, it is unlikely to create the same multiplier effects as savings that are on-lent through modern financial institutions. For this reason, a service that could link deposit collection to the formal banking sector would hold the promise of benefitting both savers and the broader economy through improved intermediation.
\end{abstract}

To examine this, we conducted an experiment in which employees of the National Savings Bank (NSB) worked as deposit collectors for 12 months in semirural areas of Sri Lanka. NSB employed a technological innovation to deliver remote banking services in a highly credible way: a mobile POS device links the agent to the bank's computer system via the mobile telecom network, allowing the depositor to receive a receipt providing full account information,

\footnotetext{
* De Mel: Department of Economics, University of Peradeniya, Peradeniya 20400, Sri Lanka (e-mail: demel. suresh@gmail.com); McIntosh: Graduate School of International Relations and Pacific Studies, University of California-San Diego, La Jolla, CA 92093 (e-mail: ctmcintosh@ucsd.edu); Woodruff: Department of Economics, University of Warwick, Coventry CV4 7AL, UK (e-mail: c.woodruff@warwick.ac.uk). This project would not be possible without the collaboration of the National Savings Bank, particularly the Bandarawela and Mahiyangana branches, or without funding provided by the Consortium for Financial Services and Poverty (CFSP) and the Center for Competitive Advantage in the Global Economy. We thank Mike Callen for assistance with the project,and Shawn Cole for comments. Kandy Consulting Group carried out all of the surveys and treatment logistics.

$\uparrow$ To view additional materials, and author disclosure statement(s),visit the article page at http://dx.doi.org/10.1257/aer.103.3.387.
}

including the amount of the latest deposit. Withdrawals can be made only at the bank, providing a form of savings commitment via asymmetric costs of deposit and withdrawal. Weekly home visits by the POS agents resulted in significant increases in bank savings and overall savings, as reported in Callen et al. (2012).

While frequent visits by POS-enabled bank agents are effective at increasing savings, they are unlikely to be cost effective given the salaries and capital costs involved. In this paper we report on a subsequent experiment which altered the collection method to reduce collection costs. The experiment allows us to "unbundle" various attributes of the weekly home POS visit in order to understand which components of the weekly home visit are central to its impact. Theory points us in several directions. First, there is the question of the frequency at which people are prompted to transact (Field and Pande 2008, McIntosh 2008). Next, there is the question of salience; the extent to which an individual is actively prompted to save (Karlan et al. 2010). Finally, frequent face-to-face collection may be effective simply because it inculcates a habit of saving.

The unbundling experiment altered the frequency of savings by switching some households from weekly to biweekly (fortnightly) collection. We altered the salience of savings by having the bank install a neighborhood savings lockbox rather than sending the deposit collector door-to-door. Only the bank agent has the key to this box, and POS receipts are left behind once the box has been collected on its regular schedule. We switched both control and treatment areas to the box treatment, leaving us with the six treatment combinations illustrated in Figure 1. These are Weekly Home (the original treatment, which we refer to as "treatment"), Treatment to Biweekly Home (the experiment in decreasing frequency), Treatment to Weekly Box (the experiment in decreasing salience), 


\section{Baseline data collection months 1-5}

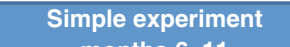

months 6-11
Behavioral experiment

months 12-18

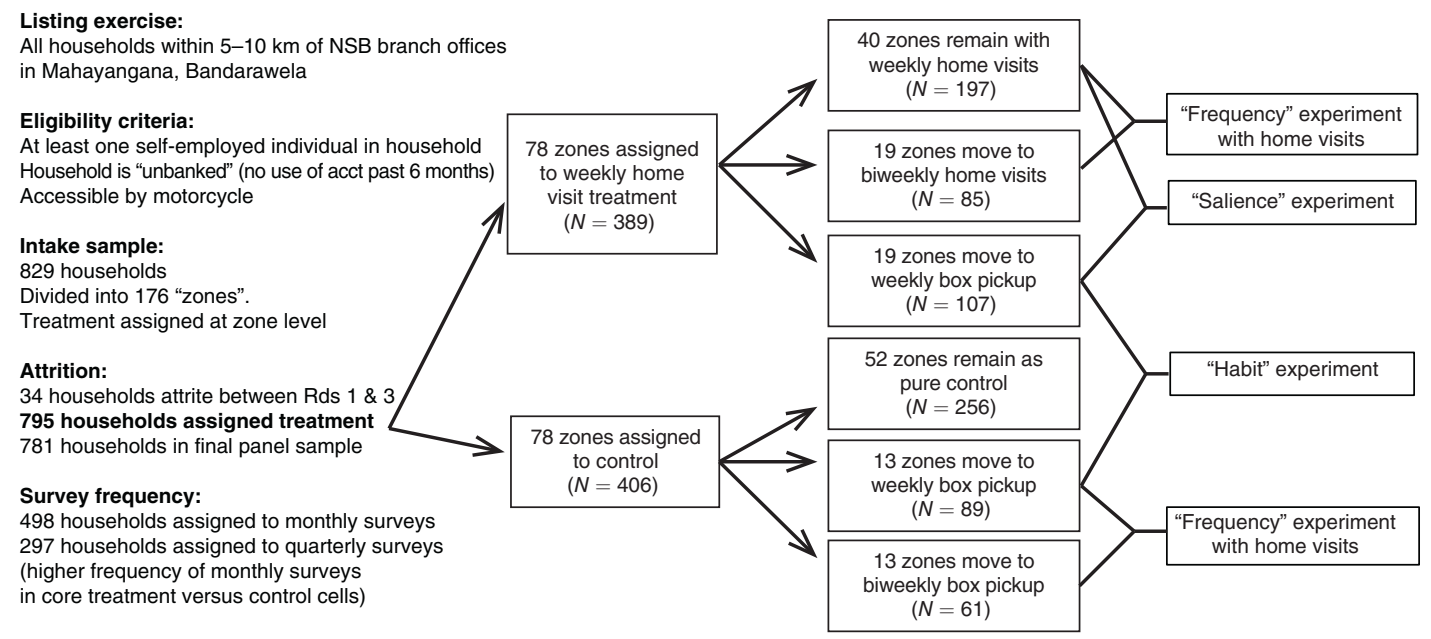

Figure 1. Research Design

and then Control to Weekly Box, Control to Biweekly Box, and Pure Control. Comparison of the Treatment to Weekly Box and Control to Weekly Box provides an estimate of the extent of habit formation, since a group with and without a history of Weekly Box collection are switched to the same treatment status (Weekly Box).

Our results indicate that substantially less expensive deposit collection techniques are almost as effective as Weekly Home visits at generating deposits for the participating bank. Surprisingly, the average NSB account balances of the group switched from Control to Biweekly Box treatment grew just as fast as the Weekly Home treatment over the first nine months. The less radical changes had similarly negligible effects on deposits collected by NSB. Collection frequency has a strong effect on deposit amounts, but no effect on overall savings. Decreasing the salience of savings sharply decreases the number of transactions, but we see no decrease in total bank savings when participants are switched from Weekly Home to Weekly Box. A history of savings improves the frequency, deposit size, and total bank savings amount when the weekly box is offered, but the effect of this habit formation appears to be transitory. The community savings lockbox appears to be a viable financial service for the institution, but one whose effect on total household savings will be negligible.

\section{Unbundling Collection Services: Design}

The experimental design is shown in Figure 1. The original sample was obtained from areas 5-10 kilometers away from NSB branches in the towns of Bandarawela and Mahiyangana. The bank was already using POS terminals in these branches to collect deposits from merchants in a radius of about one kilometer from the branch. We agreed to design a collection program for more remote areas not then served by the POS program. Within the target area, we identified 156 distinct clusters of houses. In August 2010 we conducted a listing exercise, gathering data on employment and use of banking services for 3,657 households in the 156 clusters.

The listing identified households in which no member had any transaction with a bank in the previous month, and in which a primary income earner received income with a frequency of at least once per week. In practice, this produced a sample which includes a high percentage of microenterprise owners-mainly small shops or vendors of vegetables and other agricultural products. From the listing, we selected a sample 
TABle 1-Overall Impact of Treatment UnbundLing

\begin{tabular}{|c|c|c|c|c|c|c|}
\hline & \multicolumn{2}{|c|}{ Administrative data } & \multicolumn{4}{|c|}{ Survey data } \\
\hline & $\begin{array}{l}\text { Program } \\
\text { deposits per } \\
\text { month } \\
(1)\end{array}$ & $\begin{array}{c}\text { Program } \\
\text { withdrawals } \\
\text { per month } \\
\text { (2) }\end{array}$ & $\begin{array}{c}\text { Total formal } \\
\text { transactions } \\
\text { per month } \\
\text { (3) }\end{array}$ & $\begin{array}{l}\text { Total bank } \\
\text { savings per } \\
\text { month } \\
\text { (4) }\end{array}$ & $\begin{array}{l}\text { Total nonbank } \\
\text { savings per } \\
\text { month } \\
(5)\end{array}$ & $\begin{array}{l}\text { Total } \\
\text { savings per } \\
\text { month } \\
(6)\end{array}$ \\
\hline Treated (weekly home visits) & $\begin{array}{c}614.3 * * * \\
(-36.010)\end{array}$ & $\begin{array}{l}266.0 * * * \\
(25.7)\end{array}$ & $\begin{array}{l}1.567 * * * \\
(0.1)\end{array}$ & $\begin{array}{l}596.9^{* * * *} \\
(116.2)\end{array}$ & $\begin{array}{c}17.9 \\
(250.2)\end{array}$ & $\begin{array}{l}763.1 * * \\
(321.5)\end{array}$ \\
\hline Treatment to biweekly home & $\begin{array}{c}-77.770 \\
(-59.570)\end{array}$ & $\begin{array}{c}14.9 \\
(66.4)\end{array}$ & $\begin{array}{l}-0.693 \text { *** } \\
(0.1)\end{array}$ & $\begin{array}{c}93.3 \\
(177.9)\end{array}$ & $\begin{array}{c}30.7 \\
(483.5)\end{array}$ & $\begin{array}{c}21.1 \\
(578.3)\end{array}$ \\
\hline Treatment to weekly box & $\begin{array}{c}-37.510 \\
(-67.380)\end{array}$ & $\begin{array}{c}21.7 \\
(63.1)\end{array}$ & $\begin{array}{l}-0.394 * * * \\
(0.1)\end{array}$ & $\begin{array}{c}170.3 \\
(153.9)\end{array}$ & $\begin{array}{l}-21.5 \\
(292.8)\end{array}$ & $\begin{array}{c}275.5 \\
(400.3)\end{array}$ \\
\hline Control to weekly box & $\begin{array}{r}238.0 * * * \\
(-45.690)\end{array}$ & $\begin{array}{c}83.2 \\
(60.1)\end{array}$ & $\begin{array}{l}0.985^{* * * *} \\
(0.1)\end{array}$ & $\begin{array}{c}135.9 \\
(160.8)\end{array}$ & $\begin{array}{r}-523.5 \\
(321.2)\end{array}$ & $\begin{array}{r}-436.9 \\
(467.0)\end{array}$ \\
\hline Control to biweekly box & $\begin{array}{c}246.4 * * * \\
(-53.490)\end{array}$ & $\begin{array}{c}23.1 \\
(40.9)\end{array}$ & $\begin{array}{l}0.447 * * * \\
(0.1)\end{array}$ & $\begin{array}{c}275.4 \\
(199.4)\end{array}$ & $\begin{array}{c}-486.3 \\
(481.0)\end{array}$ & $\begin{array}{c}-276.8 \\
(569.2)\end{array}$ \\
\hline Constant & $\begin{array}{r}1.684 * \\
(-12.430)\end{array}$ & $\begin{array}{c}2.3 \\
(9.1)\end{array}$ & $\begin{array}{l}0.517 * * * \\
(0.0)\end{array}$ & $\begin{array}{l}455.6^{* * * *} \\
(68.3)\end{array}$ & $\begin{array}{c}3,954 * * * \\
(182.3)\end{array}$ & $\begin{array}{c}4,646^{* * * *} \\
(233.6)\end{array}$ \\
\hline Observations & 10,875 & 10,875 & 10,875 & 10,875 & 10,875 & 10,875 \\
\hline$R^{2}$ & 0.146 & 0.042 & 0.249 & 0.014 & 0.014 & 0.014 \\
\hline Number of individuals & 781 & 781 & 781 & 781 & 781 & 781 \\
\hline Mean in control group & 0 & 0 & 0.5 & 744.1 & $4,284.4$ & $5,222.0$ \\
\hline
\end{tabular}

Notes: Regressions are OLS models with individual-level fixed effects, month dummies, and standard errors clustered at the individual level to account for autocorrelation. Standard errors are reported in parentheses. The treatment effect for the "Treated" group is estimated relative to the control group, the "Treatment to biweekly home" and "Treatment to weekly box" are estimated relative to the weekly home visit treatment. The "Control to weekly box" and "Control to biweekly box" are estimated relative to the control group outcome. Regressions include data from rounds $2-18$. Parameter estimates statistically different than zero at 99 percent $(* * *), 95$ percent $(* *)$, and 90 percent $(*)$ confidence.

of 795 individuals. We surveyed 498 of these individuals monthly with a detailed expenditure and cash flow survey to identify changes in both formal and informal savings behavior. The other 297 were surveyed quarterly so that we could measure the effect of more frequent surveys on behavior. The analysis in this paper uses 18 survey rounds for the "monthly survey" households and eight survey rounds in the "quarterly sample," as well as administrative data from NSB on all treatment accounts.

In December 2010 NSB began weekly doorto-door collection services for individuals in 78 clusters selected at random. The collection services generated savings in NSB accounts and increased the aggregate savings of households receiving the services. (See Callen et al. 2012 for a more detailed discussion of the effects of the program on household savings and other outcomes.) While the door-to-door services generated savings, it quickly became clear that the amount being collected from the households made the door-to-door collection service economically unviable for NSB. Thus, in May 2011 - six months after the beginning of collections-we designed the series of "tweaks" described in Figure 1 to study the effects of lower cost collection methods.

\section{Results: Impact on Deposits, Transactions, and Aggregate Savings}

Both the original experiment and the tweaks are balanced on key variables. (See online Appendix.) Using the full sample, Table 1 shows the effects of each tweak relative to the original treatment/control outcomes. The first two columns use administrative data from NSB, and the last four columns use the survey data. The movements of individuals from treatment are measured relative to those remaining in the Weekly Home treatment, and the movements of individuals from control are measured relative to those remaining in control. 
The administrative data show the positive effect of Weekly Home collection on deposits at NSB (column 1), deposits in any formal bank (column 4) and total monthly savings (column 6). There is no change in the nonbank savings of the Weekly Home treatment group, providing further evidence that the formal savings generated under this treatment are truly additional rather than simply representing a shift from informal to formal savings.

Relative to the base treatment outcomes, the change to biweekly collections or to box rather than home collection decreases deposits by a small and highly insignificant amount (column 1). The number of transactions falls, but there are no significant changes in other outcomes. Relative to the control outcomes, the initiation of weekly or biweekly box collection results in higher deposits at NSB - though the average is slightly less than half the level of the Weekly Home treatment (column 1). The measured effect of the total bank savings increases by a similar amount, though the greater imprecision of this measure means it is not statistically significant. However, there is no indication that total savings have increased among those shifted from control to box collection (column 5). Indeed, the measured effect of total savings relative to those remaining in the control group is negative, though very insignificant.

The results in Table 1 compare the effect of the various treatments to either the Weekly Home or Control groups. The Weekly Home treatment bundles face-to-face reminders and frequent collection. We can unbundle the components of the Weekly Home collection by comparing specific treatments bilaterally. We do this in Table 2. The top panel compares Weekly Home to Biweekly Home collection, thus isolating the effect of frequency. The middle panel compares Weekly Home visits to Weekly Box collection, isolating the effect of reminders and salience. The bottom panel compares the Weekly Home to Box transition with the Control to Box transition, isolating the habit formation coming from six months of Weekly Home collection. ${ }^{\text {I }}$

\footnotetext{
${ }^{1}$ The switch to boxes changes more than salience. The face-to-face collections may lead to feeling pressure to deposit something given the collector's effort. Depositors may not trust the box as a safe place to leave deposits. On the first issue, we find that about 25 percent of those switching from Weekly Home to Weekly Box treatment deposited
}

We find that frequency has an effect on NSB deposits, but an almost equal effect on NSB withdrawals. The net is that there is no effect on total NSB savings. Total bank savings and total savings are also unaffected. The shift from home to box collection also has a very small effect on any outcomes. If anything, it appears the formal savings goes $u p$ in this group with the shift to box collection. Finally, there does seem to be a role for habit formation. Among the two groups shifted to Weekly Box collection, those who had been in the Weekly Home treatment have significantly higher NSB/bank savings. This difference is significant using either the administrative (column 2) or survey (column 4) data.

When we examine the time-path of the changes, we find that the frequency effect is important near the time of the transition, but the effect appears to fade over time. (See Figure F1 in the online Appendix.) Salience, on the other hand, has little effect initially, but the effect grows over time. Perhaps the habits formed through six months of Weekly Home collections are enough to sustain the level of savings without face-to-face reminders for some period, but the effect of these habits wears off over time.

We might worry that the frequent surveying has an effect on the behavior of the participants. We examined this by testing whether the treatment effects differ in samples surveyed monthly rather than quarterly. We find that there is a positive effect for both frequency and salience in the quarterly survey sample, but the effect disappears in the monthly survey sample. This suggests that the reminder provided by the survey itself may substitute for the reminders provided by face-to-face and frequent collections. (See online Appendix Table T1.) When instead we examine survey effects for the households that switch from being controls to having access to the deposit box we see no differences between the monthly and quarterly samples. This lack of survey effects is potentially important given that the next section shows the biweekly box treatment to be economically viable for the

something but never more than an average of 50 Sri Lankan rupees (LKR) per week in any month of Weekly Home collection. Half of these stop making deposits entirely after the switch to box. Among those making pretweak deposits averaging $100 \mathrm{LKR}$, only 17 percent never use the box to make a deposit. This suggests that trust is not a first-order issue. 
TABLE 2

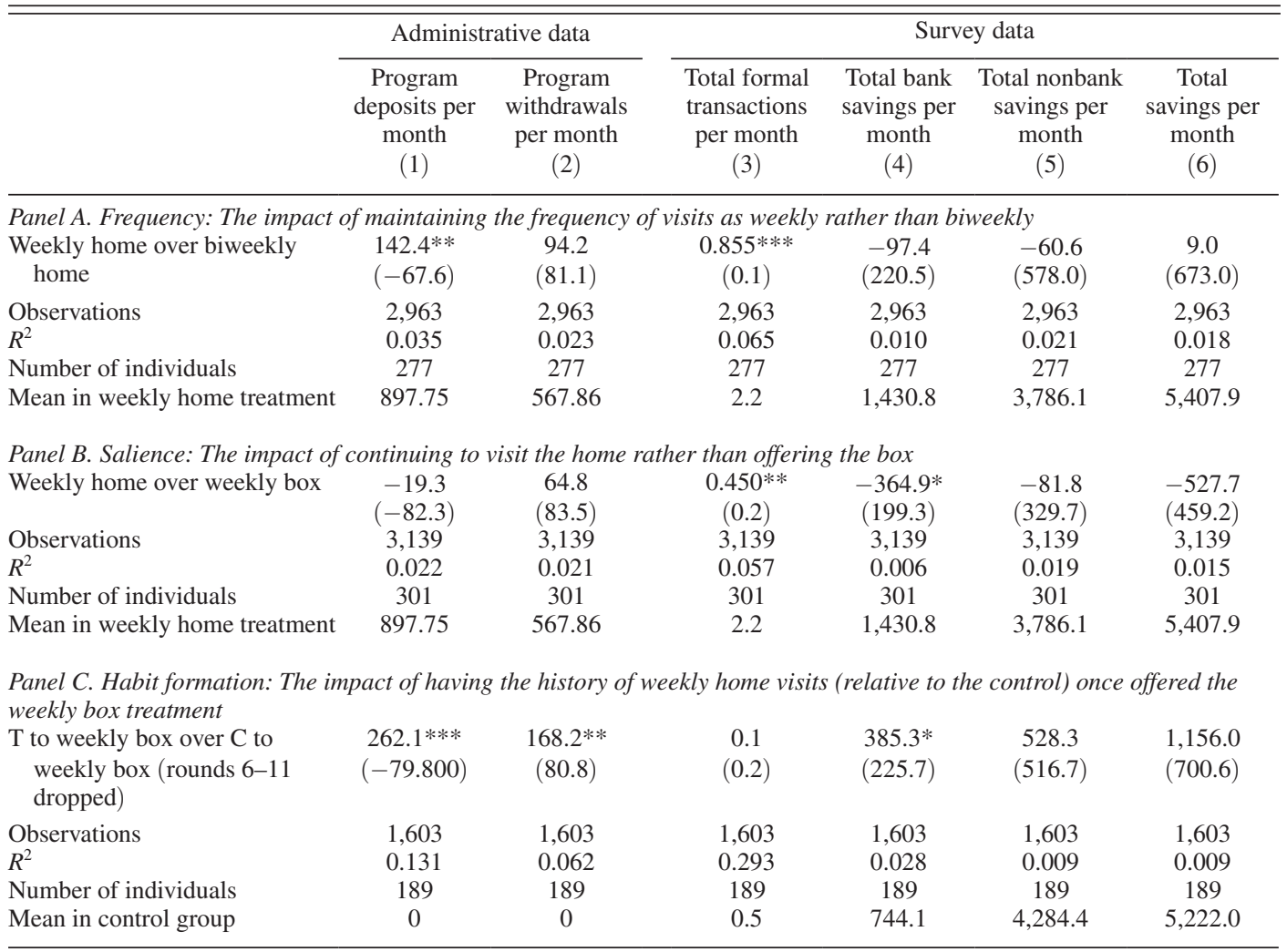

Notes: Regressions are OLS models with individual-level fixed effects, month dummies, and standard errors clustered at the individual level to account for autocorrelation. Standard errors are reported in parentheses. Regressions include data from rounds 6-18 for the Frequency and Salience panels, and from rounds $2-5$ and 12-18 for the Habit Formation panel. Parameter estimates statistically different than zero at 99 percent $(* * *), 95$ percent $(* *)$, and 90 percent $(*)$.

bank; there is no indication that the efficacy of the control-to-box switch is driven by the high-frequency surveys.

\section{Economics of Deposit Collection}

Weekly face-to-face collections are almost certainly too costly to be profitable for banks. The lowest cost collection method we examine is the Biweekly Box collection. We find that collections in the group shifting from Control to Biweekly box are as robust from the start as collections from the Weekly Home sample. The Control to Biweekly Box group has somewhat lower collections when the data are Winsorized at the ninety-eighth percentile. But even then the deposit levels are 75 percent of the Weekly Home levels. (See online Appendix.)
We examine the economics of POS deposit collection using all of the methods with which we experimented. We estimate the costs including labor-the POS terminal operator and administrative support at the bank-and capital - the costs of POS terminal, motorcycle, and collection boxes. Based on data from the bank, we estimate the annual cost of the door-to-door collection is just over 800,000 LKR, and the annual cost for the biweekly box collection is 232,000 LKR. The largest single cost is the salary of the deposit collector, almost 500,000 LKR for the Weekly Home collections, but only a quarter as much for the Biweekly Box collections.

Against this cost, we estimate the benefit of the collection services. We use the difference between the return on government debt 
(12.5 percent per year as of December 2012) and the interest rate paid on savings accounts ( 5 percent) as the net return on intermediated funds. The balances in all of the project accounts summed to 3.8 million LKR at the end of December 2011. Since total balances increased by 38 percent between end of July and end of October and by 11 percent between end of October and end of December, we first assume that the balances will be 20 percent higher by end of 2012. The POS collectors also take deposits from people outside the sample, and the collections will be opened to those in the control group at the end of 2012. We account for this in a rough way by assuming that the total balances from nonsample households would be half the level of the sample households. This yields balances of 6.8 million LKR and net intermediation revenues of $513,000 \mathrm{LKR}$, or $256,000 \mathrm{LKR}$ per branch, an amount which exceeds the estimated cost of generating the funds. These very rough estimates suggest that the Biweekly Box collection services may be viable for NSB. ${ }^{2}$

For areas in which the mobile phone agent network is well developed, we can also compare the cost of POS collections with mobile phone based collection services. Mobile operators in Sri Lanka pay their wholesaler/ retailer network of top-up service agents about 8 percent of revenues in fees. Using the 8 percent rate and data on transactions through the POS terminals - that is, excluding deposits made in person at the bank branch-the fees from a mobile-phone based product $(249,000$ LKR) would have exceeded the cost of the POS operation. Of course, these fees represent average costs of maintaining the agent network; the marginal costs are likely substantially lower. Nevertheless, the comparison suggests that personal collections using POS technology may well maintain a place in the menu of banks.

\footnotetext{
${ }^{2}$ An additional consideration is that NSB has a social mission of providing financial services to low-income households. However, we are unable to quantify this.
}

\section{Conclusions}

Frequent face-to-face deposit collection leads households to increase their aggregate savings over the intermediate term, with increased balances not offset by any decrease in informal savings. But balances in the deposit-taking bank also increase with less frequent collections made through lockboxes placed in communities. We find that salience, frequency, and habits all affect the number of transactions, but have only smaller and temporary effects on the level of deposits. The experiment suggests that even with rural households of modest income levels, deposit collection through community lockboxes may be financially viable for banks. Of course, collection through community lockboxes requires a degree of trust and security that may not be present in all locations.

\section{REFERENCES}

Ashraf, Nava, Dean Karlan, and Wesley Yin. 2006. "Deposit Collectors." B E Journal of Economic Analysis and Policy: Advances in Economic Analysis and Policy 6 (2): 1-22.

Callen, Michael, Suresh de Mel, Craig McIntosh, and Christopher Woodruff, 2012. "What are the Headwaters of Formal Savings? Experimental Evidence from Sri Lanka." Unpublished.

-Field, Erica, and Rohini Pande. 2008. "Repayment Frequency and Default in Microfinance: Evidence from India." Journal of the European Economic Association 6 (2-3): 501-09.

Karlan, Dean, Margaret McConnell, Sendhil Mullainathan, and Jonathan Zinman. 2010. "Getting to the Top of Mind: How Reminders Increase Saving." National Bureau of Economic Research Working Paper 16205.

-McIntosh, Craig. 2008. "Estimating Treatment Effects from Spatial Policy Experiments: An Application to Ugandan Microfinance." Review of Economics and Statistics 90 (1): 15-28.

Rutherford, Stuart, 2000. The Poor and Their Money. New York: Oxford University Press. 